\title{
Erratum to: Resident perceptions of advanced laparoscopic skills training
}

\author{
Vanessa N. Palter $\cdot$ Neil Orzech $\cdot$ Rajesh Aggarwal • \\ Allan Okrainec • Teodor P. Grantcharov
}

Published online: 7 February 2011

(C) Springer Science+Business Media, LLC 2011

Erratum to: Surg Endosc (2010) 24:2830-2834

DOI 10.1007/s00464-010-1058-2

Appendix 1 was inadvertently omitted in this article, which was published in Volume 24, Number 11, pp. 2830-2834. It is provided here.

The online version of the original article can be found under doi:10.1007/s00464-010-1058-2.

V. N. Palter $(\bowtie)$

Toronto General Hospital, The Wilson Centre, 200 Elizabeth

Street, 1ES 565, Toronto, ON M5G 2C4, Canada

e-mail:Vanessa.palter@utoronto.ca

N. Orzech

Department of General Surgery, The University of Toronto,

Toronto, ON M5S 1A1, Canada

R. Aggarwal

Department of Biosurgery and Surgical Technology,

Imperial College, London SW7 2AZ, UK

A. Okrainec

Department of General Surgery, The Toronto Western Hospital,

Toronto, ON M5T 2S8, Canada

T. P. Grantcharov

Department of General Surgery, St. Michael's Hospital,

Toronto, ON M5B 1W8, Canada 


\section{Appendix 1: Resident Experience Questionnaire}

\section{INSTRUCTIONS}

Please fill out the following questionnaire regarding your experiences while in your residency training program. The questionnaire should take approximately 5 minutes. Individual responses will be kept confidential.

\section{DEMOGRAPHICS}

1. PGY year?

2. Gender? Male __ Female

\section{OPERATIVE EXPERIENCE}

1. How many Laparoscopic cases have you observed or assisted with since the beginning of your residency? (NB: where you are not the primary surgeon)

$$
\text { None } \quad 1-5 \quad 5-10 \quad 10-15 \quad 15-20 \quad 20-30 \quad 30-40 \quad>40
$$

2. How many Laparoscopic cases have you been the primary surgeon for since the beginning of your residency?

$$
\text { None } \quad 1-5 \quad 5-10 \quad 10-15 \quad 15-20 \quad 20-30 \quad 30-40 \quad>40
$$

3. How many Laparoscopic Cholecystecomies have you been the primary surgeon for since the beginning of your residency (you dissected the Triangle of Calot)?

$$
\text { None } \quad 1-5 \quad 5-10 \quad 10-15 \quad 15-20 \quad 20-30 \quad 30-40 \quad>40
$$

4. At what stage of training did you perform your first laparoscopic case as primary surgeon?

$$
\text { PGY -1 PGY-2 PGY-3 }
$$

5. What procedure did you perform for your first laparoscopic case as the principle surgeon?

$$
\begin{array}{ll}
\text { a. Laparoscopic cholecystectomy } \\
\text { b. Laparoscopic appendectomy } \\
\text { c. Laparoscopic colorectal surgery } \\
\text { d. Laparoscopic foregut surgery } \\
\text { e. Laparoscopic bariatric surgery } \\
\text { f. other (please specify) }
\end{array}
$$

6. Approximately, on average, the number of Laparoscopic cases per month that you act as:
a. Primary surgeon?
None $\quad 1-2 \quad 2-5 \quad 5-8 \quad 8-10 \quad>10$
b. $1^{\text {st }}$ Assistant?

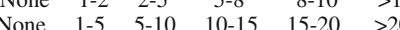
c. Observer?
None $\begin{array}{lllll}1-5 & 5-10 & 10-15 & 15-20 & >20\end{array}$

7. Approximately, on average, the number of each the following you have performed as the primary surgeon since the start of your residency:

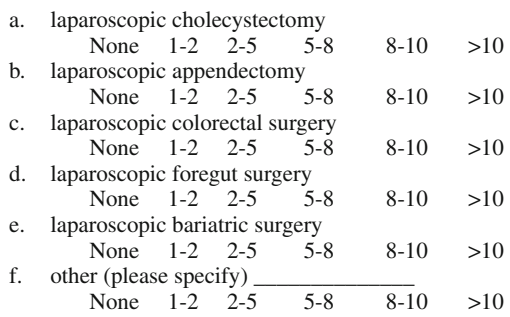

8. How would you rate the volume of laparoscopic operative cases you perform as the primary surgeon?

$$
\begin{array}{lllllll}
\text { Too Little } & 1 & 2 & 3 & 4 & 5 & \text { Too Much }
\end{array}
$$

9. Do you believe you had enough training in laparoscopy prior to performing a laparoscopic case as the primary surgeon?

$\begin{array}{lllllll}\text { I don't have enough } & 1 & 2 & 3 & 4 & 5 & \text { I have more than enough }\end{array}$

10. How would you rate the volume of instruction you have received with laparoscopic suturing?

I don't have enough $\quad 1 \quad 2 \quad 3 \quad 4 \quad 4 \quad 5 \quad$ I have more than enough

11. How would you rate your experience/level of skill with laparoscopic suturing?

I don't have enough $\quad 1 \quad 2 \quad 3 \quad 3 \quad 4 \quad 5 \quad$ I have more than enough 
THE NEXT SET OF QUESTIONS ARE TO BE COMPLETED

UPON COMPLETION OF THE COURSE

LAPAROSCOPIC SUTURING AND JEJUNO-JEJUNOSTOMY EXPERIENCE

1. Please rank which of the following LAPAROSCOPIC SUTURING assessment tools you preferred using (PLACE A NUMBER FROM 1-4 next to each of the following, where $1=$ best and $4=$ worst ):

FLS Black Box Suturing task

FLS Black Box Nissen Fundoplication Model Task

_ LapMentor Virtual Reality Surgical Simulator Suturing Task

_ Animal Model

2. Please rank the overall educational value of each of the following LAPAROSCOPIC SUTURING assessment tools:

a. FLS Black Box Suturing task

$$
\begin{array}{ccccccc}
1 & 2 & 3 & \begin{array}{c}
4 \\
\text { Neutral }
\end{array} & 5 & 6 & \begin{array}{c}
7 \\
\text { Not useful }
\end{array} \\
& & & & \text { Extremely Helpful }
\end{array}
$$

b. FLS Black Box Nissen Fundoplication Model Task

$$
\begin{array}{ccccccc}
1 & 2 & 3 & 4 & 5 & 6 & \begin{array}{c}
7 \\
\text { Not useful }
\end{array} \\
& & \text { Extremely Helpful }
\end{array}
$$

c. LapMentor Virtual Reality Surgical Simulator Suturing Task

$$
\begin{array}{ccccccc}
1 & 2 & 3 & \begin{array}{c}
4 \\
\text { Neutral }
\end{array} & 5 & 6 & \begin{array}{c}
7 \\
\text { Not useful }
\end{array} \\
& & & & \text { Extremely Helpful }
\end{array}
$$

d. Animal Model

$\begin{array}{ccccccc}1 & 2 & 3 & \begin{array}{c}4 \\ \text { Neutral }\end{array} & 5 & 6 & \begin{array}{c}7 \\ \text { Not useful }\end{array} \\ & & & & \text { Extremely Helpful }\end{array}$

Thank you for your participation! 